\title{
The Investigation of Wind Energy Potential in Order to Estimate Power Plants in Baladeh Mazandaran, Iran
}

\author{
S. Asghar Gholamian ${ }^{\mathrm{a}^{*}}$, S. Bagher Soltani ${ }^{\mathrm{b}}$, R. Ilka ${ }^{\mathrm{a}}$ \\ ${ }^{a}$ Electrical Engineering Department of Babol University of Technology, Babol, Iran \\ ${ }^{b}$ Islamic Republic of Iran Meteorological Organization (IRIMO)-Meteorological General Office of Mazandaran Province, Head of Marine Meteorology \\ Research Group \\ *Corresponding author: gholamian@nit.ac.ir
}

Article history

Received :13 February 2012

Received in revised form :2 July

2012

Accepted :13 August 2012

Graphical abstract

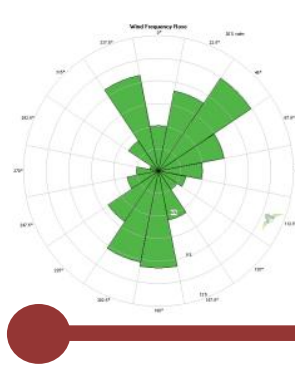

\subsection{INTRODUCTION}

Today, wind power is a fully established branch on the electricity market and it is treated accordingly. The energy gain is not the only criteria to be considered when installing new wind turbines; cost efficiency, the impact on the environment and the impact on the electric grid are some of the important issues of significant interest when making decisions about new wind turbine installations [1].

Wind energy is one of the most important and promising renewable energy resources in the world. The penetration of the wind energy in electrical system is rapidly increasing. Currently, a growing number of small size wind farms used as Distributed generation (DG) sources are located within the distribution system [7].

Kaviani evaluated wind energy by for a five years statistics of 60 synoptic weather station between 1981 and 1985 [2]. This survey showed that Zabol station, with the power of $1894 \mathrm{kWh}$ for each square meter of the surface that is swept by propellers, has the best condition for establishing wind turbines. Also Jusk, Bandar Lenge and Kish station with 756, 618 and $569 \mathrm{kWh}$ respectively [2].

Because of Iran's specific geography and wind speed, there is a possibility of producing $10000 \mathrm{MW}$ electricity from wind turbines in this country (internal report of Iran renewable energy organization) [2]. Baladeh is one of the 15 synoptic weather stations in Mazandaran which is located in the middle of Alborz mountains with 36 12' latitude and $51 \quad 48$ ' longtitude.

This station started its activity as a synoptic station since September 2006 and its atmospheric data is recorded daily at the times of 03, 06, 09, 12 and 15 according to UTC. This paper used a total 7900 recorded data of wind speed and direction from the beginning of establishing this station up to end of 2009, duration of 40 months. Baladeh station is chosen because it has the most average wind speed among 15 stations of Mazandaran. Annual average wind speed of this station is $3.5 \mathrm{~m} / \mathrm{s}$ in a 4-years period from 2006 to 2009 which is the most among the other 15 stations. Therefore, it seems that this station is the best place in Mazandarn from the viewpoint of wind energy potential and energy production.

\subsection{RESEARCH METHODOLOGY}

\subsection{Introducing Weibull Probability Distribution Function}

In order to calculate the likely power output from a given wind turbine it is necessary to understand the wind in the planned turbine location. It is very easy to find the average wind speed in a 
location. Probability density distribution function of weibull wind speed is used to calculate the wind energy [3, 4 and 6].

$$
f(V)=\frac{k}{c}\left(\frac{V}{c}\right)^{k-1} e^{-\left(\frac{V}{c}\right)^{k}}
$$

In which $\mathrm{V}$ is wind speed and $\mathrm{c}$ and $\mathrm{k}$ are scale and shape parameters, respectively. These parameters can be calculated using Maximum likelihood method:

$$
\begin{aligned}
& \mathrm{k}=\left(\frac{\sum_{\mathrm{i}=1}^{\mathrm{n}} \mathrm{V}_{\mathrm{i}}^{\mathrm{k}} \ln \left(\mathrm{V}_{\mathrm{i}}\right)}{\sum_{\mathrm{i}=1}^{\mathrm{n}} \mathrm{V}_{\mathrm{i}}^{\mathrm{k}}}-\frac{\sum_{\mathrm{i}=1}^{\mathrm{n}} \ln \left(\mathrm{V}_{\mathrm{i}}\right)}{\mathrm{n}}\right)^{-1} \\
& \mathrm{c}=\left(\frac{1}{\mathrm{n}} \sum_{\mathrm{i}=1}^{\mathrm{n}} \mathrm{V}_{\mathrm{i}}^{\mathrm{k}}\right)^{\frac{1}{\mathrm{k}}}
\end{aligned}
$$

In (1), (2) and (3) equations $V_{i}$, is wind speed in period $i$ and $n$ number of nonzero wind speed [6].

\subsection{Variation of Weibull Probability Distribution Function} According to $\mathrm{k}$ and $\mathrm{c}$

a) $\mathrm{k}$ is constant $(\mathrm{k}=5)$ and c variant:

Figure 1 shows the variation of weibull probability distribution function for different values of $\mathrm{c}$ while $\mathrm{k}$ is constant $(\mathrm{k}=5)$ :

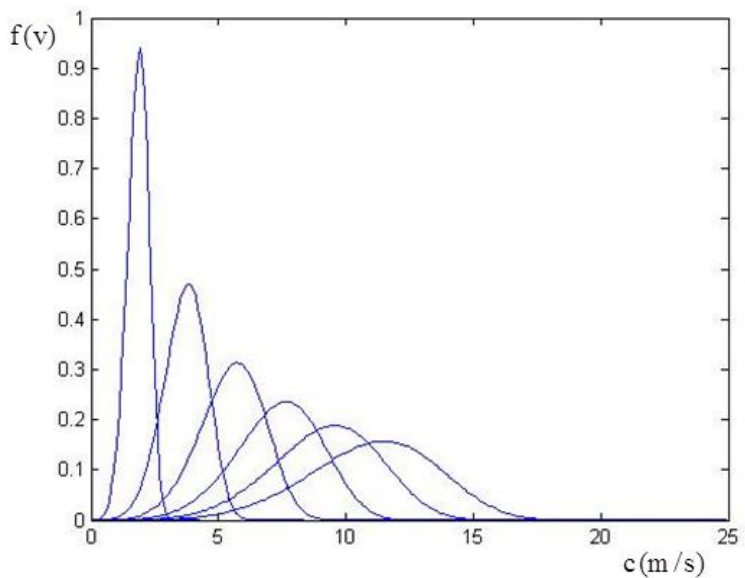

Figure 1 Variation of weibull probability distribution function for different values of $\mathrm{c}$

The curve peak inclines to higher wind speed by increase in c as shown in the Figure 2, while probability of peak curve decreases.

b) c is constant ( $c=5)$ and $\mathrm{k}$ variant

Figure 2 shows the variation of weibull probability distribution function for some values of $\mathrm{k}(\mathrm{k}=2,4,6,8,10,12)$ while $\mathrm{c}$ is constant $(\mathrm{c}=5 \mathrm{~m} / \mathrm{s})$.

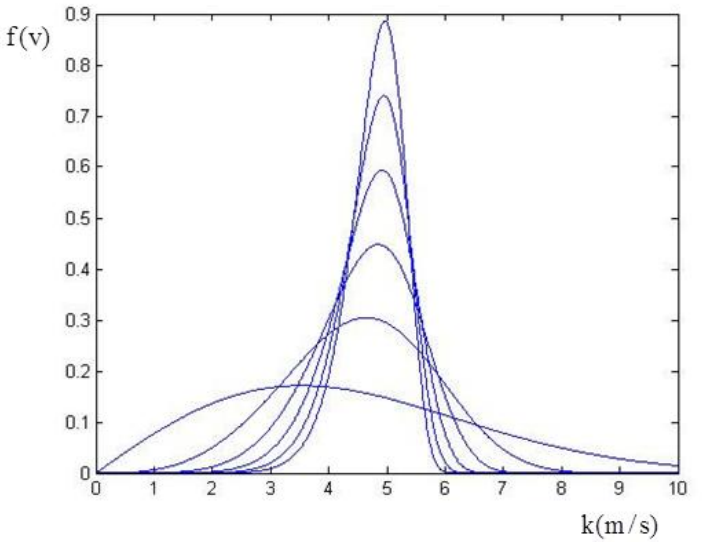

Figure 2 Variation of weibull probability distribution function for some values of $\mathrm{k}$

As shown in the Figure 2 when $\mathrm{k}$ increases curve peak inclines to higher wind speed; while curve peak probability increases.

\subsection{Wind Energy Potential Calculation}

Wind energy which passes through surface A of turbine propeller is presented as follow:

$$
\mathrm{P}(\mathrm{V})=\frac{1}{3} \rho A \mathrm{~V}^{3}
$$

is weather density of the area $\left(1.009 \mathrm{Kg} / \mathrm{m}^{3}\right)$. Wind power density of a station based on weibull distribution is calculated as follows:

$$
\frac{\mathrm{P}}{\mathrm{A}}=\int_{0}^{\infty} \mathrm{P}(\mathrm{V}) \mathrm{f}(\mathrm{V}) \mathrm{dV}=\frac{1}{2} \rho c^{3} \Gamma\left(\frac{\mathrm{k}+3}{\mathrm{k}}\right)
$$

Energy produced by turbine in period $\mathrm{T}$ is:

$$
E_{T W}=T \int_{V_{1}}^{V_{R}} P(V) f(V) d V+T \int_{V_{R}}^{V_{O}} P_{R} f(V) d V
$$

$P_{R}$ is constant nominal power in nominal speed $V_{R}$. Substituting $\mathrm{P}(\mathrm{V})$ and $\mathrm{f}(\mathrm{V})$ in the above equation gives:

$$
\mathrm{E}_{\mathrm{TW}}=\frac{\rho}{2} \mathrm{TA}\left(\int_{\mathrm{V}_{\mathrm{R}}}^{\mathrm{V}_{\mathrm{O}}} \mathrm{V}^{3} \frac{\mathrm{k}}{\mathrm{c}}\left(\frac{\mathrm{V}}{\mathrm{c}}\right)^{\mathrm{k}-1} \cdot \mathrm{e}^{-\left(\frac{\mathrm{V}}{\mathrm{c}}\right)^{\mathrm{k}}} \mathrm{dV}+\mathrm{V}_{\mathrm{R}}^{3} \int_{\mathrm{V}_{\mathrm{R}}}^{\mathrm{V}_{\mathrm{O}}} \frac{\mathrm{k}}{\mathrm{c}}\left(\frac{\mathrm{V}}{\mathrm{c}}\right)^{\mathrm{k}-1} \mathrm{e}^{-\left(\frac{\mathrm{V}}{\mathrm{c}}\right)^{\mathrm{k}}} \mathrm{dV}\right.
$$

To evaluate the desirability of wind potential, it is common to determine wind power density at the height of 50 meters.

As the wind data in weather station is for 10 meters height, it should be adapted into 50 meters height. For this purpose Least Square Power Law is used [5]:

$$
\mathrm{V}(\mathrm{z})=\mathrm{V}_{\mathrm{R}}\left(\frac{\mathrm{z}}{\mathrm{z}_{\mathrm{R}}}\right)^{\alpha}
$$

In which

and $\mathrm{V}(\mathrm{z})$ and $\mathrm{V}(\mathrm{R})$ are wind speed at the height of 10 meters and $z_{R}$ respectively. Using the above 
equations and Table1, wind power density at 50 meters and wind potential class can be calculated.

Table 1 Wind power classification (from http://rredc.nrel.gov)

\begin{tabular}{lll}
\hline $\begin{array}{l}\text { Wind } \\
\text { class }\end{array}$ & power & \multicolumn{2}{l}{$\begin{array}{l}\text { 50-meters wind } \\
\text { power } \\
\left(\mathbf{W} / \mathbf{m}^{2}\right)\end{array}$} & Condition \\
& $0-200$ & \\
\hline 1 & $200-300$ & Weak \\
2 & $300-400$ & Medium \\
3 & $400-500$ & Partly good \\
4 & $500-600$ & Good \\
5 & $600-800$ & Very good \\
6 & $800-2000$ & Great \\
7 & & Very great \\
\hline
\end{tabular}

\subsection{EVALUATING WIND ENERGY POTENTIAL IN BALADEH STATION}

Baladeh synoptic weather station is 2120 meters height above sea level. The average wind speed of this station is $3.6 \mathrm{~m} / \mathrm{s}$ which is the highest among the other 15 stations of Mazandaran. Hence data of wind speed and direction in this station was analyzed by Windographer software. This station started its activity on September 2006 as a synoptic station. Atmospheric data of this station are recorded 5 times a day in hours 03, 06, 09, 12, 15 according to UTC time. This paper has used all the recorded data of wind speed and direction containing 7900 recorded data of wind speed and direction from the beginning of establishing this station up to end of 2009 a duration of 40 months. Figure 3 shows average around 10-meters wind speed from 2006 to 2009.

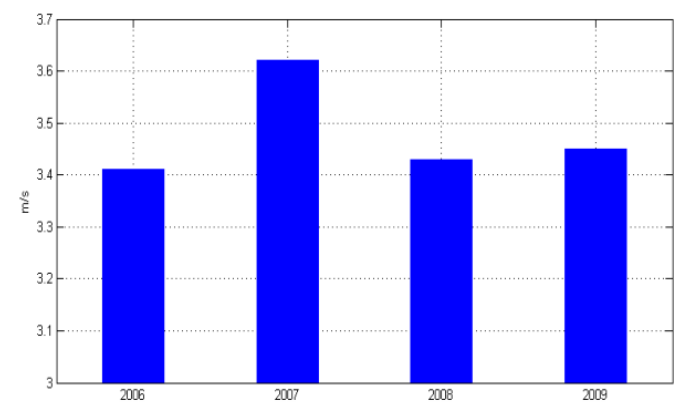

Figure 3 Average annual 10-meters wind speed variations diagram of Baladeh station from 2006 to 2009

Figure 4 shows the average values, daily minimum average and daily maximum average and monthly absolute maximum for wind speed from 2006 to 2009.

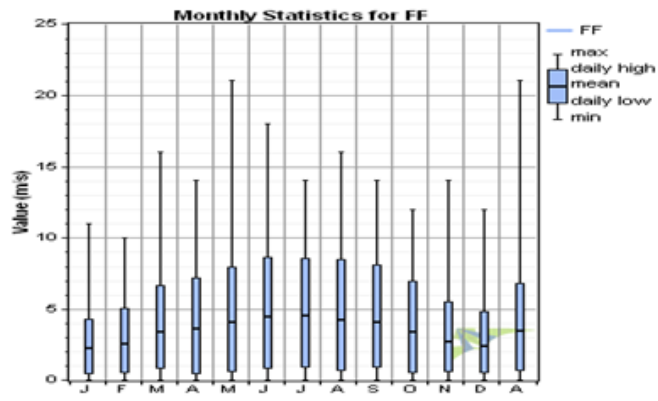

Figure 4 Box diagram of monthly wind speed average variation and other parameters from September 2006 to the end of 2009
As seen in Figure 4, average wind speed is higher in hot months of the year that is, June, July and August while wind speed absolute maximum is the most in May. Figure 5 shows Windrose of this 40 months period. Figure 5 shows wind occurrence abundance is more in south, northeast and northwest directions. However, distribution of wave energy in different directions requires calculating the weibull factors.

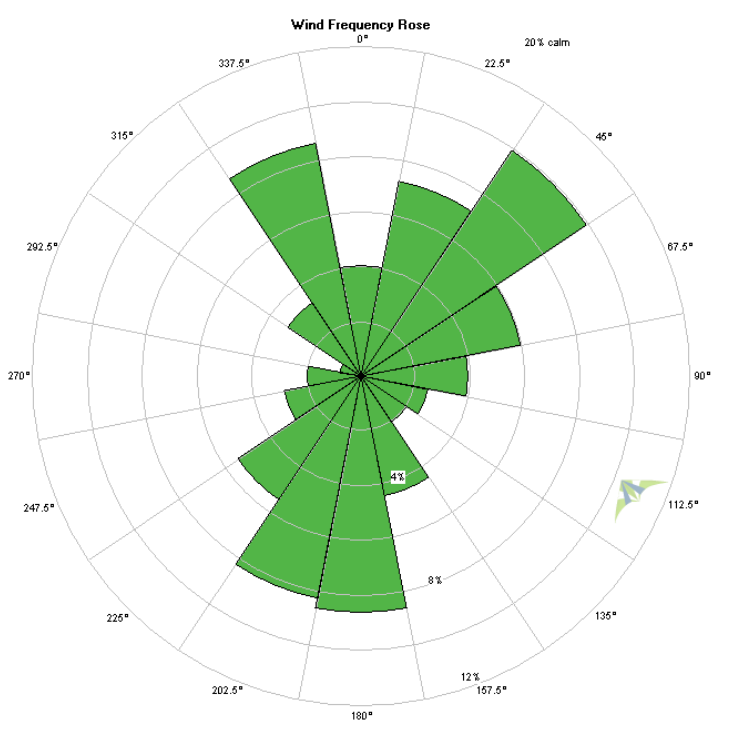

Figure 5 Windrose of Baladeh weather station from September 2006 to the end of 2009

Diagram of Figure 6 shows the fitting curve of weibull probability distribution in the 10-meters wind speed data. Factors $\mathrm{k}$ and $\mathrm{c}$ based on Maximum Likelihood method are 1.44 and 1.09 $\mathrm{m} / \mathrm{s}$, respectively.

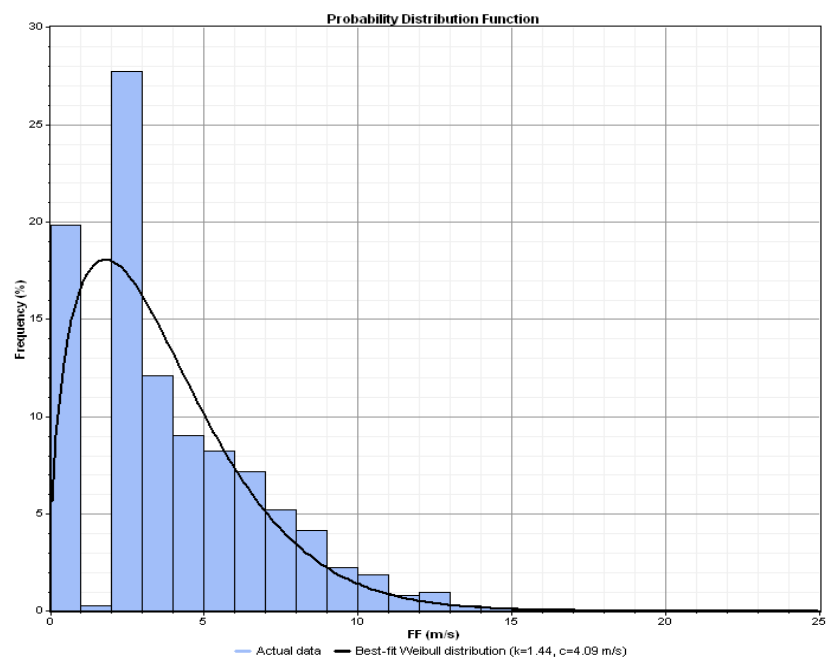

Figure 6 10-meters wind speed probability distribution and fitting curve of weibull distribution and weibull's $\mathrm{k}$ and $\mathrm{c}$ factors (based on Maximum Likelihood method) in Baladeh weather station from September 2006 to the end of 2009

Based on calculations, annual average of 10-meters wind energy density is $74.976 \mathrm{~W} / \mathrm{m}^{2}$. This value is 147.40 for 50 -meters height which is categorized as weak potential according to Table1. Figures 7 and 8 show annual and monthly average of 50meters wind energy density, respectively. 


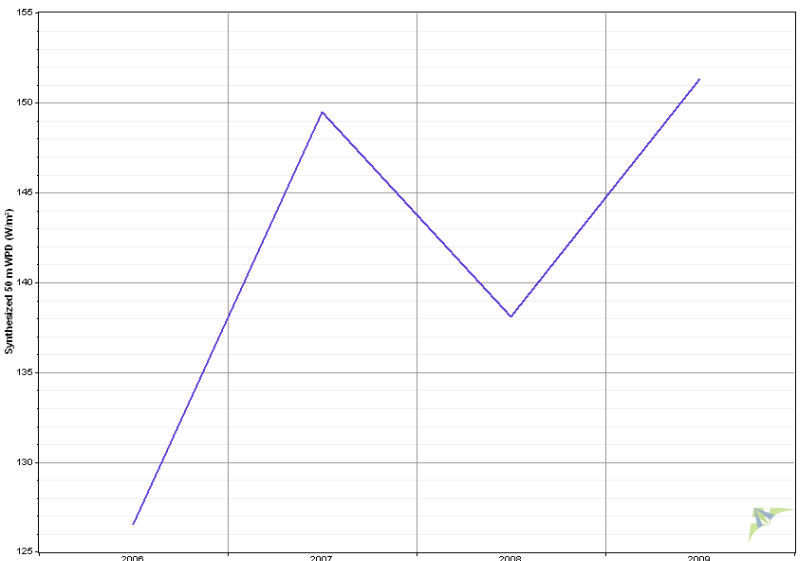

Figure 7 Annual average of 50-meters wind energy density $\left(\mathrm{W} / \mathrm{m}^{2}\right)$ calculated by weibull's factors $\mathrm{k}$ and c (based on Maximum Likelihood method) in Baladeh weather station from September 2006 to the end of 2009

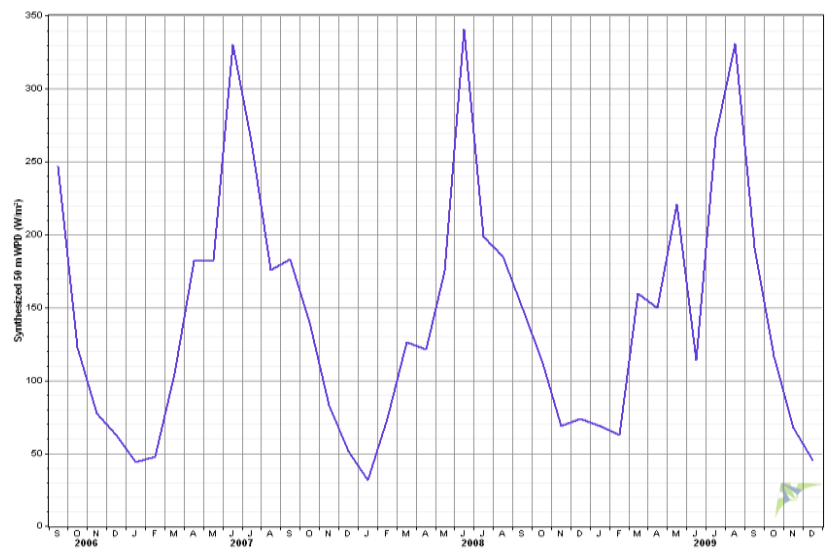

Figure 8 50-meters wind energy density $\left(\mathrm{W} / \mathrm{m}^{2}\right)$ in each months calculated by weibull's factors $\mathrm{k}$ and $\mathrm{c}$ (based on Maximum Likelihood method) in Baladeh weather station from September 2006 to the end of 2009

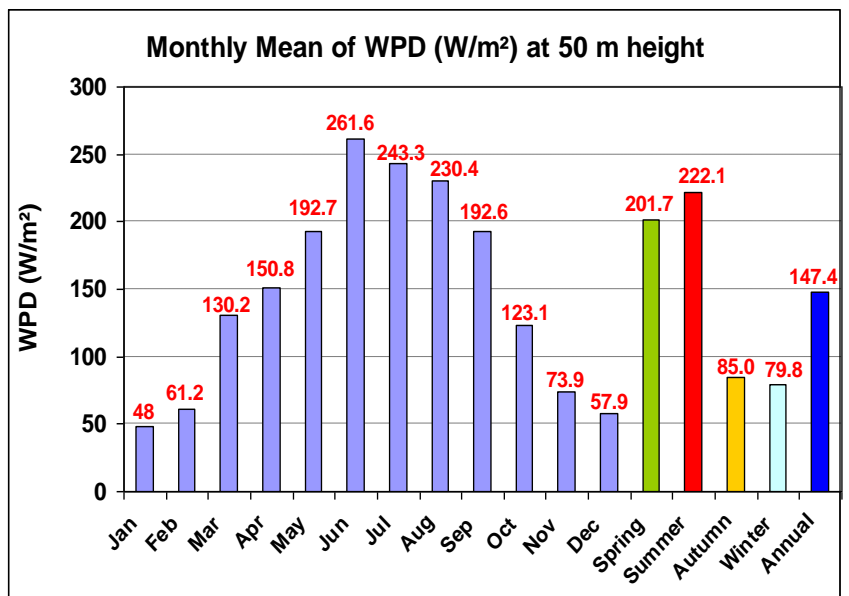

Figure 9 Monthly average of 50-meters wind energy density $\left(\mathrm{W} / \mathrm{m}^{2}\right)$ calculated by weibull's factors $\mathrm{k}$ and $\mathrm{c}$ (based on Maximum Likelihood method) in Baladeh weather station from September 2006 to the end of 2009

Condition of monthly average of 50-meters wind power density is shown in Figure 9. As shown in Figure 9, wind power density is more than $200 \mathrm{~W} / \mathrm{m}^{2}$ in 3 hot months of the year that is
June, July and August which suggests medium potential condition in these months.

Figure 10 shows average 10-meters wind energy density in various directions for 50-meters height. Comparing Figures 6 and 10 , clearly shows that although wind occurrence abundance is more in south, northeast and northwest directions, wind power density is much more in the northwest direction.

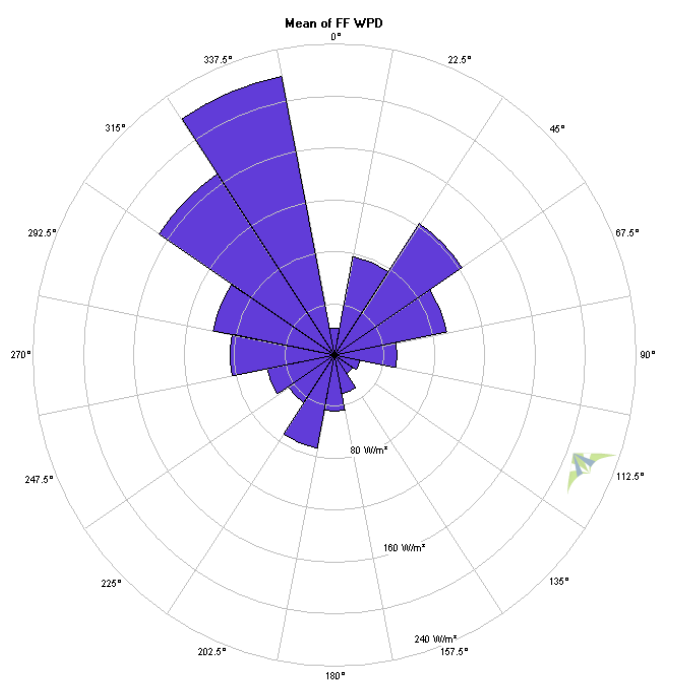

Figure 10 Monthly average of 10 -meters wind energy density $\left(\mathrm{W} / \mathrm{m}^{2}\right)$ calculated by weibull's factors $\mathrm{k}$ and $\mathrm{c}$ (based on Maximum Likelihood method) in Baladeh weather station from September 2006 to the end of 2009

\subsection{CONCLUSION}

Average 10-meters wind speed of Baladeh weather station is 3.6 $\mathrm{m} / \mathrm{s}$ which is the highest among the other 15 synoptic stations of Mazandaran. This will be more than $4 \mathrm{~m} / \mathrm{s}$ in hot months that is from May to September. Major results of this paper are classified as follow:

(1) As shown in Windrose it is observed that wind occurrence abundance is more in northeast and northwest directions. Wind power density is calculated using weibull probability distribution function for 10-meters winds of this station and calculating factors $\mathrm{k}$ and $\mathrm{c}$ based on Maximum Likelihood method.

(2) Annual factors $\mathrm{k}$ and $\mathrm{c}$ for 10 -meters wind are 1.44 and 4.09 $\mathrm{m} / \mathrm{s}$, respectively. Correspondingly for 50 -meters wind these factors are 1.44 and $5.13 \mathrm{~m} / \mathrm{s}$. Regarding these values, annual average of 10 and 50-meters wind power density are 74.98 and $147.40 \mathrm{~W} / \mathrm{m}^{2}$, respectively; which are classified at class 1 of Table 1 that is weak potential.

(3) However, 50-meters wind power density is more than 200 $\mathrm{W} / \mathrm{m}^{2}$ in the 3 hot months of the year that is June, July and August which suggests medium potential condition in these months.

(4) In addition, although wind occurrence abundance is more in south, the northeast and northwest directions, wind power density is much more in northwest direction.

\section{References}

[1] Spera David A. 1994. Wind Turbine Technology. ASME PRESS.

[2] Kaviani, M. 1995. Assessment of Wind Turbines and Wind Energy Potential in Iran. Journal of Geographical Research. 
[3] Akdag, S. A., Dinlar, A. 2009. A New Method to Estimate Weibull Parameters for Wind Energy Applications. Energy Conversion and Management. 50: 1761-1766.

[4] Ullah, I., Chaudhry, Q. Z. and Chipperfield, A. J. 2010. An Evaluation of Wind Energy Potential at Kati Bandar, Pakistan. Renewable and Sustainable Energy Reviews. 14: 856-861.

[5] Archer, C. L., and M. Z. Jacobson. 2003. Spatial and Temporal Distribution of U.S. Winds and Wind Power at $80 \mathrm{M}$ Derived from Measurements. J. Geophys. Res. 108(D9): 4289. doi: 10.1029/2002JD002076.
[6] Akpinar, S., Akpinar, E. K. 2009. Estimation of Wind Energy Potential Using Finite Mixture Distribution Models. Energy Conversion and Management. 50: 877-884.

[7] Jingjing Zhaoa, Xin Li a, Jutao Haob and Jiping Lua. 2010. Reactive Power Control of Wind Farm Made Up with Doubly Fed Induction Generators in Distribution System. Electric Power Systems Research. 698-706. 